number of trainees in the system. The application and review process would also help to ensure that only researchers with the ability and desire to become independent investigators receive the awards. If few awards were available, they would probably become extremely competitive and could significantly reduce the number of postdocs in the pipeline, at least in the United States.

However, to serve as a practical alternative, these fellowships must provide postdocs with the same workplace benefits that grant-supported postdocs enjoy. That is not uniformly the case. For example, in the United States, some fellowship recipients are left to shop for health insurance on their own. When one of us (V.C.) moved from a university-sponsored salaried position to a fellowship, she lost her health insurance through the university and had to find another provider. Although the 2010 passage of the US Affordable Care Act has made health care more affordable for individuals, such a demand poses an unnecessary burden on postdocs. Instead, why not simply give all postdocs access to the same health benefits that graduate students or conventional university employees receive?

There are other challenges: boosting the number of fellowships would also increase the burden on the grant-review system. And, because research grants would not cover postdoc salaries, the arrangement could leave PIs in a precarious position - with the funds to pay for research supplies and equipment, but fewer incentives to offer postdocs to join their lab. PIs would also no longer be able to hire postdocs to cover the roles of

technicians and staff scientists.

If postdocs receive greater independence, PIs will lose some control, so they may have to find other resources to conduct their research. But this could be good for science: having postdocs strike out away from the beaten path will bring fresh ideas and approaches to the table. For both of us, getting a fellowship enabled us to cut a path that was separate from the dominant research area in each of our mentors' labs. The experience of trying to define a new scientific direction has been most useful for us, even as our paths diverge. $n$ SEE NEWS FEATURE P. 22

Viviane Callier is a freelance science writer and contractor at the US National Cancer Institute in Bethesda, Maryland. Jessica Polka is a postdoctoral researcher at Harvard Medical School in Boston, Massachusetts.

\title{
EMPLOYMENT TERMS
}

\section{California postdocs win new rights}

\section{Career development a priority in university contract.}

\section{BY HELEN SHEN}

$\mathrm{F}$ US groups including the National Academies of Sciences, Engineering, and Medicine and the National Institutes of Health, some universities are initiating policies to give postdoctoral researchers more time and latitude for career exploration.

A contract between the University of California (UC) and its postdoc labour union gives postdocs across the ten-campus system the right to pursue career-development activities on paid time. "That's a pretty big milestone," says Belinda Huang, executive director of the US National Postdoctoral Association in Washington DC. "UC is being very explicit here, where other universities have not necessarily been explicit."

The agreement, which follows months of negotiation and covers the university's roughly 6,500 postdocs, took effect on 1 November, and will last until 30 September 2016. It also includes new employment protections for international postdocs and establishes a committee to consider financial assistance for child-care expenses.

The university's move echoes national-level support for such activities. In 2014, the White House Office of Management and Budget stated that it recognizes the 'dual role' of postdocs as both employees and trainees and that it expects them to be "actively engaged in their training and career development" while conducting research supported by government grants.

\section{TIME TROUBLES}

But it remains to be seen whether these measures will spur greater day-to-day participation in the courses, mentoring programmes and other career-exploration resources that already exist at many US universities, including the UC. For UC postdocs who had previously skipped such programmes because of pressure to focus on a conventional academic career, the new contract could provide an encouraging nudge. For others, however, even contract-enshrined 'permission' may not be enough. "The truth is, I don't have time to do all of these activities," says neuroscientist Wan-Yu Hsu, a postdoc at UC San Francisco. Hsu says that the drive to produce results and to publish will probably keep her from pursuing career-development activities during the workday.

The contract also addresses immigration issues. Specifically, it offers added protections for international postdocs who get fired. The university already has a grievance process for postdocs to contest terminations. But under US immigration law, many international postdocs must return to their home countries immediately on termination, leaving them to argue their cases from afar.

The UC agreement states that if the grievance process cannot be resolved at an earlier point, and the postdoc has had to leave the country, the university will help to sponsor a travel visa for the postdoc to return to the United States to participate in their final arbitration hearing. If the postdoc is successful in their case, the university will reimburse the travel costs. If he or she is not successful, the union will foot the bill.

Roughly two-thirds of UC postdocs come from outside the United States, but terminations are rare, and those that are not resolved before arbitration are even rarer, says Anke Schennink, president of the postdoc union. Nevertheless, the provision adds a measure of security, she says.

One of the outstanding issues in the contract is whether and how the university will help with child-care costs. A handful of institutions - including Stanford University in California, Cornell University in Ithaca, New York, and Princeton University in New Jersey - offer subsidies or discounts for child care. But the expenses remain a serious issue for many others across the country, and contribute to women leaving the scientific workforce, says Huang.

The postdoc union had pushed for the creation of a financial-assistance programme to help postdocs with child-care expenses - the university already offers the benefit to graduate students - but the two parties could not agree on terms. Instead, the university and union have agreed to form a committee to discuss the issue in the coming year. "We're hoping to make more progress in the next round," says Schennink. - 